\title{
Segregated vowels: Language variation and dialect features among Gothenburg youth-Corrigendum
}

\author{
JOHAN GROSS
}

doi:10.1017/S0954394518000169, Published by Cambridge University Press, 9 January 2019.

A reference appeared incorrectly in the above publication (Gross, 2019).

The correct in-text citation is "(Kohn, 2018)".

The correct reference entry is "Kohn, Mary. (2018). The impact of de facto and de jure segregation on African American English in the New South. In J. Reaser, E. Wilbanks, K. Wojcik, \& W. Wolfram (eds.), Language variety in the New South: Contemporary Perspectives on Change and Variation. Chapel Hill: University of North Carolina. 223-240.”

\section{REFERENCE}

Gross, Johan. (2019). Segregated vowels: Language variation and dialect features among Gothenburg youth. Language Variation and Change 30:315-336. doi:10.1017/S0954394518000169 